\title{
El número nueve en la medicina popular
}

Posiblemente los restos más antiguos que delatan el empleo simbólico del número nueve estén en el yacimiento de La Ferrasie, en la Dordoña (suroeste de Francia), que tiene unos 50.000 años de antigüedad. Se trata de nueve pequeños túmulos regulares, alineados en filas de tres, hechos con una mezcla de ceniza de hogar y grava, en el último de los cuales fue enterrado un niño que nació muerto. Estos nueve túmulos (remedos del regazo materno) se interpretan como los nueve ciclos lunares que, igual que conducen al nacimiento del hombre, deben conducirle a su renacimiento ${ }^{1}$.

Introduciendo un poco de orden en la pequeña selva de hechos, episodios y valores simbólicos relacionados con el número nueve, podríamos establecer los siguientes grupos ${ }^{2}$ :

1. Éste que acabamos de ver, relacionado con el período de gestación, que a veces se disfraza de procesos creativos, de búsquedas que acaban dando frutos: Démeter busca a su hija Perséfone durante nueve días por todo el mundo. Leto, seducida por Zeus y embarazada de Apolo y de Artemisa, sufre dolores de parto durante nueve días y nueve noches. Las Musas nacen de Zeus en nueve noches de amor. Los dioses griegos que han cometido perjurio deben pasar nueve años alejados del Olimpo. El arca de Deucalión navega durante nueve días antes de tocar tierra en el monte Parnaso. Vishnú se encarna nueve veces. El cinabrio de los alquimistas sólo se hace potable a la novena transmutación. El Hak de los sufíes, última etapa de la Vía de Beatitud, está emparentado con el número nueve.

1 Piero y Alberto ANGELA, La extraordinaria bistoria del hombre (Madrid: Mondadori, 1992), pp. 216-217.

2 Ver Gertrude JOBER, Dictionary of Mythology, Folklore and Symbols (New York: The Scarecrow Press, 1962), vol. 2, s.v. "nine"; Juan Eduardo Cirlot, Diccionario de símbolos (Barcelona: Labor, 1969), s.v. "números"; Diccionarios Rioduero: Símbolos (Madrid: Rioduero, 1983), s.v. "nueve" y "noventa y nueve"; Jean ChEVAlIER y Alain GHEERBRANT, Diccionario de los símbolos (Barcelona: Herder, $2 .^{2}$ ed., 1988), s.v. "nueve"; Olivier BEIGBEDER, Léxico de los símbolos (Madrid: Encuentro, 1989), s.v. "números". 
2. Otro, una especie de consecuencia del anterior, relacionado con la culminación, con la perfección que se alcanza tras ese proceso (el feto está completo al séptimo mes, pero es perfecto al noveno): Entre los budistas chinos - para los que el cielo tiene 9 alturas y 9.999 esquinas-, entre los hindúes, los turcos, los mongoles, los aztecas, en Dante (cuya escatología sabemos que debe tanto a la musulmana), hay nueve esferas celestes y nueve infernales. Nueve son los aspectos simbólicos del universo, entre los órficos. Los ángeles forman nueve coros. Los chuvache del Volga agrupan a sus dioses de nueve en nueve. La pagoda de nueve pisos china simboliza el cielo. Entre los hebreos es símbolo de la verdad, ya que, multiplicado por cualquier número, se reproduce a sí mismo por adición mística. Jesús muere a la novena hora. Litúrgicamente, la novena representa el tiempo completo, la terminación. En relación con la perfección del nueve, el 99 era el número de la palabra amén entre los cristianos y 99 son las cuentas del rosario mahometano. Representa también el fin de un ciclo; el fin y el comienzo por ser el último de la serie de cifras; la multiplicidad que retorna a la unidad.

3. Otro, en el que el número nueve es una extensión del tres: es la totalidad de los tres mundos, cada uno de los cuales es un triángulo. Representa la perfección por ser el triple del número sagrado tres. Para los platónicos de Alejandría, la Trinidad divina primordial se subdivide en tres, formando nueve principios. El infierno cristiano tiene tres puertas de latón, tres de hierro y tres de diamante. Nueve son las Musas ${ }^{3}$. (El simbolismo de este grupo en última instancia parece que es lunar. "Los chinos se prosternan nueve veces ante su emperador; en África se ha visto a un soberano superior exigir de otro inferior que antes de hablarle besase nueve veces el polvo" ${ }^{4}$. En la más remota antigüedad, el astro asociado al hombre era la luna ${ }^{5}$. Y la luna es por excelencia el centro en torno al que giraba el antiguo culto a las distintas formas de la Gran Diosa, del cual el que, en países de gran tradición matriarcal, se rinde a la Virgen

\footnotetext{
"Se habla también de nueve cielos ( $y$ de nueve dioses, nueve ramas del Árbol Cósmico, etc.), número místico que se explica según todo hace pensar como $3 \times 3$ ". (Mircea EliAde, El chamanismo y las técnicas arcaicas del éxtasis, México: Fondo de Cultura Económica, 1960, p. 219. Véase también n. 45, en p. 412, donde se ofrece bibliografía sobre el significado religioso y cosmológico del número nueve).

+ Collin DE Plancy, Diccionario infernal (Barcelona: Táber, 1968), s.v. "nueve".

" Quedan restos de ello en el género gramatical del sustantivo que la designa en árabe y en antiguo alemán, por ejemplo; también en tradiciones japonesas, en baladas rumanas y en mitos mesopotámicos.
} 
es una supervivencia ${ }^{6}$. "Los miembros de mi familia - dice Robert Graves ${ }^{7}$ - han hecho siempre nueve reverencias ante la luna nueva (...) porque tres es el número asociado con la luna: nueva, llena y menguante, y nueve es tres veces tres. (...) Nueve es el número que defiende el poder de la muerte en la vida, y de la vida en la muerte: de las diosas Hécate y Perséfone").

4. Y un último que tiene que ver con las nueve aberturas del cuerpo humano, que son las vías de comunicación con el mundo. (En el esoterismo islámico el hombre tiene nueve sentidos.)

Resumiendo al máximo estos grupos, el nueve tiene relación simbólica con la gestación, con el número tres y con los orificios del cuerpo.

En los repertorios de medicina popular ${ }^{8}$, aparecen con insistencia los números impares. En Portugal, por ejemplo, incluso se considera adverso el número par: "Um número par de banhos é desventajoso, devendo preferir-se sempre um número ímpar" ". Ya se ha llamado la atención sobre el hecho. "Es muy vieja la creencia en números fastos y nefastos y singularmente la virtud sagrada y maravillosa del número 3. Estas prácticas adivinatorias, astrológicas y mágicas cree Déchelette que las propagaron los druidas por Occidente porque los celtas pensaban que "le nombre impair plait aux dieux". 10. No creemos que el origen del empleo de fórmulas impares sea celta. Los celtas que llegaron a España no ocuparon zonas en las que encontramos números impares en este tipo de remedios.

\footnotetext{
- El reloj que había en el claustro de la Universidad de Salamanca, exculpido en el último tercio del siglo XVI, tenía, entre otras, unas figuras de "los tres Reyes Magos con dos ángeles que se humillaban todas las mañanas a las nueve en punto ante la imagen de la Virgen que estaba encima". Enrique SÁNCHEZ REYES, "Lenguas de piedra (sobre los enigmas del claustro universitario salmantino)", Boletin de la Biblioteca Ménendez y Pelayo (núm. extraordinario en homenaje a D. Miguel Artigas), 1931, p. 262.

7 "Prácticas de la superstición", en La comida de los centauros y otros ensayos (Madrid: Alianza, 1994), p. 132.

8 Ver la extensa - aunque no exhaustiva - bibliografía que proporciona Pilar MONTERO CURIEL, “Medicina popular y plantas curativas. Bibliografía crítica (1883-1988)", RDTP, XLV (1990), pp. 89-101.

9 José Diogo Ribeiro, "Turkel folklórico", Revista Lusitana, 20 (1917), p. 73. En nota 3 añade: "Nas fórmulas e práticas folklóricas, o emprêgo de números pares é muito restricto; os ímpares 3, 9, 7 e 5 sao ahi os preferentesn.

10 Jesús TABOADA, "La noche de San Juan en Galicia", RDTP, VIII (1952), p. 614.
} 
De estos números, el nueve es uno de los que más veces interviene en operaciones terapéuticas. Veamos bajo qué formas puede aparecer ${ }^{11}$ :

a) A veces se emplean nueve partes de un ingrediente, o nueve veces uno o más ingredientes. La anemia en Galicia se curaba bebiendo nueve vasos de agua, cada uno de una fuente distinta ${ }^{12}$. En Redondela (Pontevedra), para tratar el aire de envidia, o de excomulgado, se tomaban, entre otras cosas, nueve ramitas de laurel y nueve de trubiscón ${ }^{13}$. La cura de la queratitis en Asturias se hacía con nueve granos de trigo, nueve de mijo y nueve de sal ${ }^{14}$.

En ocasiones se emplean -esto es más raro- nueve ingredientes: en Salamanca, sobre los pechos congestionados y doloridos por el exceso de flujo láctico, se aplicaba el llamado "paño de las nueve cosas" o "receta de la abuela Juana", que consistía en una "tela de hilo impregnado en la pasta resultante de freír en aceite puro de oliva, cera virgen, miel, aguardiente, tabaco negro en picadura gorda, enjundia de gallina, unas ramitas de olivo y una hoja de laurel de las bendecidas el Domingo de Ramos ${ }^{n}{ }^{15}$.

b) La operación se repite nueve veces. Para los flemones, en Andalucía, después de dar friegas en el antebrazo, se empujaban los dientes de la mandíbula superior hacia arriba con el pulgar de la mano derecha, abriendo la boca nueve veces ${ }^{16}$. Los sarnosos en Galicia se introducían, tras desnudarse, nueve veces en el agua de un río, después de lo cual se vestían nueva ropa, dejando la vieja en un árbol ${ }^{17}$.

También, aunque no sea todo el procedimiento, puede haber algo que haya que hacer nueve veces. En Fregenal de la Sierra (Badajoz), para cortar las calenturas intermitentes, el enfermo debía salir de casa antes del alba y hacer con una vara nueve rayas en la pared de una casa en la

\footnotetext{
11 Escogemos algunos de los muchos ejemplos que se podrían presentar para cada caso.

12 Elisardo Becoña Iglesias, Medicina Popular (Vigo: Ir Indo Edicions, s.f.), p. 45.

13 Víctor LIS QuiBÉN, «Medicina popular", Revista de Tradiciones Populares, I (1944), p. 259 .

14 Luciano CASTAÑón, Supersticiones y creencias de Asturias (Gijón: Ayalga, 1976), p. 57.

15 Ángel CARril, Etnomedicina. Acercamiento a la terapéutica popular (Valladolid: Castilla Ediciones [Colección Nueva Castilla, núm. 7], 1991), p. 109.

16 Alejandro Guichot y SIERRA, Supersticiones populares andaluzas (Sevilla: Editoriales Andaluzas Unidas, 1986 [la edición original es de 1883]), p. 130.

1" Jesús TABOADA, art. cit., p. 607.
} 
intersección de dos calles, contándolas en voz alta y con la cabeza vuelta para no verlas; después tenía que volver a casa por un sitio distinto sin mirar atrás, tras tirar la vara, que transmitiría el mal al primero que la cogiese ${ }^{18}$.

En ocasiones, en esa repetición se puede tener una actitud pasiva. Quien recibe nueve olas seguidas en la playa de la Lanzada (Pontevedra), o en la de los Placeres, o en la de San Francisco, a las doce de la noche de San Juan, no tendrá enfermedades en todo el año; y las mujeres estériles se harán fecundas ${ }^{19}$.

En algunos casos, nueve son las veces en que algo se debe no hacer, sino decir. El orzuelo de Cabreiroá (Pontevedra) desaparecía haciendo en el campo una casetita que se llenaba de leña y a la que se prendía fuego; el enfermo debía gritar nueve veces «iAuga, auga, que arde a casa do tío Tirizoilo!n, y otra persona había de apagar el fuego ${ }^{20}$. En Benquerança - Penamacor, Portugal-, como conclusión al remedio contra el mal de ojo $\longrightarrow$ acedente - se rezaban nueve padrenuestros, que habían de ser contados desde el final al principio ${ }^{21}$. En los años cuarenta, el Manso de Tomeza, pastequeiro pontevedrés, colocaba el enfermo del temido meigallo de rodillas, le colgaba al cuello una estola y una cruz de Caravaca, y con otra le hacía cruces sobre la cabeza a la vez que decía nueve veces: "Abernuncio us "pasteco" con espiritu tuas e de labatorios sanates cues justo Nazareno, Hijo de la Virgen María, quita o teu pauto do corpo da hechicería" 22 .

Los ejemplos más abundantes son aquellos en los que la operación se repite nueve veces pero en distintos días, es decir durante nueve días (seguidos, se especifica a veces), o se deja transcurrir un período de nueve días (como se hacía con la raíz de la chanzana, en Aragón, que debía macerar en vino el dicho número de días, cuando se usaba como remedio contra desfallecimientos por tensión baja ${ }^{23}$ ). En Paderne de Allariz

18 Publio HURTADO, Supersticiones extremeñas (Huelva, 2.. ed.: 1989 [la primera edición es de 1901]), p. 133.

19 Elisardo BeCOÑa Iglesias, op. cit., p. 53.

20 Jesús TABOADA, "La medicina popular en el valle de Monterrey (Orense)", RDTP, III (1947), p. 33.

21 Isabel Gallardo DE ÁlvAREZ, "Medicina popular y supersticiosa*, Revista de Estudios Extremeños, III (1947), pp. 184-185.

22 Víctor LIs Quibén, "Los pastequeiros de Santa Comba y San Cibrán", RDTP, III (1947), p. 501.

23 Rafael ANDOLZ, De pilmadores, curanderos y sanadores en el Alto Aragón (Zaragoza: Mira Editores, 1987), p. 64. 
(Orense), los sordos se curaban lavándose los oídos nueve días seguidos en un manantial que surgía en una peña con forma de oreja ${ }^{24}$, y los cólicos, en Guadramiro (Salamanca), tomando agua de té en ayunas durante nueve mañanas ${ }^{25}$.

Nueve días es también el plazo que se debe dejar pasar, a veces, si el remedio no funciona, como se hacía con el agua de una fuente aragonesa de la que habla Andolz ${ }^{26}$, con poder para atajar los males de bronquios, que si no mostraba su virtud en el esperado plazo de nueve días se debía dejar de tomar durante otros nueve antes de repetir la operación. Esa alternancia puede incluso ser sistemática. En Cartagena se sanaba la anemia mediante la ingestión de dientes de ajo, nueve días sí y nueve no ${ }^{27}$.

Ese número de días puede constituir el período marco, sin que ello suponga nueve acciones. En Tijarafe, La Punta (La Palma), se combatía la caída del pelo con una loción hecha con romero verde, tomillo y verbena, que había que aplicar todos los terceros días durante nueve días alternos ${ }^{28}$. Desatender la condición de cumplir los nueve días seguidos con el procedimiento, dice Ferrándiz Araujo ${ }^{29}$, podía traer en algunos casos consecuencias terribles.

En ocasiones el tratamiento es progresivo y no son intercambiables los días entre sí: en los años setenta, un curandero de Tarrasa -el Germà Joan-, para curar la mala circulación sanguínea, hacía asistir al enfermo a su consulta nueve días seguidos, y tras darle a beber el primer día un vaso de agua con una gota de yodo, le iba aumentando cada día la dosis en una gota más ${ }^{30}$.

Puede ocurrir también que el tiempo que aparece en el procedimiento no se mida en días, sino en semanas. En Mogarraz (Salamanca), nos dice

24 J. Miguel Novo GUIZÁN y Luz María MARTínez ARIAS, Un pasaje de la medicina popular de Galicia: San Martin Castelo (Viveiro, Lugo) (Lugo: Servicio Publicaciones Diputación provincial [Colección Monografías, núm. 21], 1987), p. 23.

25 Juan FRANCISCO BLANCO, Medicina y veterinaria populares en la provincia de Salamanca (Salamanca: Diputación provincial de Salamanca [Seminario de Folklore y Cultura Tradicional, Archivo de Tradiciones Salmantinas/1], 2. ${ }^{a}$ ed. ampliada, 1985), p. 31 .

26 Op. cit., p. 77.

27 Carlos FerRándiz ARAujo, Medicina popular en Cartagena (Cartagena, 1974), p. 96.

28 Talio NODA GOMEz, Medicina popular en la isla de La Palma (Sta. Cruz de La Palma: Caja General de Ahorros de Canarias, 1984), p. 177.

29 Op. cit., p. 99.

30 Montserrat Puigdengolas y Regina Miranda, la medicina popular (Barcelona: Dopesa [Col. Conèixer Catalunya], 1978), pp. 43-44. 
Ángel Carril ${ }^{31}$, para la curación de las aftas bucales, se recogía durante nueve semanas la hoja de una planta cuyo nombre no se dice por temor a que pierda su poder, se colocaba bajo una piedra y se rezaba ante ella.

No faltan tampoco los casos en que el enfermo no debe hacer nada más que permanecer inmóvil durante nueve días. En Asturias, el que estaba abierto (por enfriamiento, reúma o esfuerzo) debía permanecer en cama durante nueve días ${ }^{32}$.

Este período constituye un límite. "El período máximo para el tratamiento del "mal de ojo" se considera como nueve días. Si pasados estos el niño no se ha curado, se habrá muerto." ${ }^{33}$

c) En muchos casos las operaciones van acompañadas de un conjuro que tiene nueve "versos", o nueve miembros. Éste se usaba en Hinojosa (Salamanca) contra la erisipela: "—iDe dónde vienes, Pedro? / -Vengo de Barcelona. / _ ¿De qué? / —De curar el mal de la ampolla. / - ¿Con qué lo curas? / - Con soga de esparto / Y aceite de oliva. / Yo te curo, / Dios te sane" ${ }^{34}$. En la cura de la "espineta baja", que es el descenso del esternón, que comprime los órganos situados por debajo de éln, en Aragón se hacía una cruz sobre el punto dolorido con sebo de culebra y se decía: "Deu es nat / Deu es mort / Deu ha resucitat. / San Cosme, San Adrián (?) [sic], / Santa Magdalena / que curen esta enfermedad / del cor espaldat. / En el nombre de las tres personas / de la Santísima Trinidad. ${ }^{35}$.

Hay conjuros que consisten en la cuenta - casi siempre descendentede los nueve primeros números, con los que se asocia la enfermedad, que por simpatía también se irá reduciendo. En el País Vasco, la gangallena o gangañena, unos granos negros parecidos a sarna o a escrófula, algunas curanderas la sanaban cogiendo con la mano izquierda uno de los nueve granos de trigo o de sal gorda que antes habían puesto en un plato, apretándolo sobre uno de los granos negros y recitando: "Gangallentxu sembat tosu, bederatxi, sortxi, saspi, sei, seirik bost, bosteik lau, laurik iru, irurik pi, pirik pat, sure gangallentxu baperes" ("gangallentxu cuántos eres, nueve, ocho, siete, seis, de seis cinco, de cinco cuatro, de cuatro tres, de tres dos, de dos uno, tu gangallentxu desapareción ${ }^{36}$ ). Un conjuro pareci-

\footnotetext{
31 Op. cit., p. 12.

32 Luciano CASTAÑón, op. cit., p. 49.

33 Isabel GALLARDO DE ÁLVAREZ, art. cit., p. 185. Es superstición andaluza.

34 Luis L. CORTÉS Y VÁzQuez, "Medicina popular riberana y dos conjuros de San Martín de Castañeda., RDTP, VIII (1952), p. 531.

35 Rafael ANDOLz, op. cit., p. 101.

36 Antón ERKOREKA, Análisis de la medicina popular vasca (Bilbao: Instituto Labayru-Caja de Ahorros Vizcaína, 1985), pp. 220-222. En otro caso la oración es casi
} 
do, que nos proporciona Becoña Iglesias, se usaba (seguimos hablando en pasado porque no son testimonios de ahora mismo, aunque es muy posible que muchas de estas prácticas aún estén en uso) en muchas partes de Galicia para eliminar las lombrices. Se extendía ceniza sobre el vientre del enfermo y se cortaba con un cuchillo a la vez que se conjuraba: "Córtamas mariñas, / que sodes nove. / De nove quedades oito, / de oito quedades sete, / de sete quedades seis, / de seis quedades cinco, / de cinco quedades catro, / de catro quedades tres, / de tres quedades dúas, / de dúas quedades unha, / e esta é para Mariña" ${ }^{37}$.

En Hurchillo (Alicante) encontramos otro recitado en el que se menciona el número nueve, y que además es eneamembre: "Al huerto de Jesucristo entré, / nueve hombres encontré: / tres cavando, tres hilando (?), / tres aliacán [ictericia] cortando. / Lo corta la Virgen María / y el Espíritu Santo. / Si... (nombre del enfermo) / tiene aliacán / se le cortarán 38 .

En Andalucía, contra el dolor de muelas se decía tres veces: "Santa Polonia / Las muelas me duelen / Ya no me duelen" ${ }^{39}$, lo que equivale a un conjuro de nueve versos.

d) Puede ocurrir que -como en este último caso- el número nueve esté oculto por el tres. En Castuera e Higuera la Real (Badajoz), para sanar de calenturas tercianas y cuartanas, se iba con una vara a una encrucijada antes de que hubiese salido el sol y de que hubiese pasado nadie, se trazaba en el suelo una cruz con la vara y se decía un ensalmo; se arrojaba la vara y se echaba a correr sin mirar atrás; la vara era de adelfa y había que hacerle en la corteza nueve cortes transversales de tres en tres ${ }^{40}$. Sabemos, por el proceso inquisitorial que se siguió contra él, que el Beato de Belmonte - Castillo de Lucas no nos dice la fecha- hacía poner de rodillas al que tenía hemorroides junto a una higuera y de cara al oriente; le santiguaba y preguntaba: "¿qué corto?»; el enfermo respondía: "almorranas de mi c... (...) Luego rezaba un paternóster y Avemaría y el Beato cortaba tres palicos de la higuera, repetía lo mismo tres veces, y los nueve palicos los ponía a secar donde no les diese el humo" ${ }^{41}$. En Igara

igual, salvo que dice: ....nueve, de nueve ocho, de ocho siete...*; se hace con nueve granos de sal y durante nueve días.

3- Op. cit., pp. 41-42.

38 Francisco G. SEIJO ALONSO, Curanderismo y medicina popular (en el País Valenciano) (Alicante: Biblioteca Alicantina, 1974), pp. 142-143.

39 Alejandro Guichot y SiERRA, op. cit., pp. 128-129.

40 Publio Hurtado, op. cit., p. 130.

41 Antonio CASTILLO DE LUCAS, Folklore médico-religioso. Hagiografias paramédicas (Madrid: Ediciones Morata, 1943), p. 148. 
(San Sebastián), se hacían tres finas incisiones en las heridas inflamadas de los dedos, que después se metían tres veces al día en una vasija con leche, vino y caliza al rojo; cuando acababa la supuración, se echaban tres veces tres gotas de esnebelarra y se cubría con emplasto de caracoles ${ }^{42}$. En Ibiza el remedio contra la tensión alta se hace con "tres tanyets d'olivera, tres de sàlvia i tres de mentan ${ }^{43}$.

Puede haber más máscaras: muchos son los casos en que se usa el procedimiento de repetir alguna operación tres veces durante tres días, o de rezar tres padrenuestros, tres avemarías y tres gloriapatri. (Aunque es posible que en este último grupo nos encontremos ante un empleo reforzado del número tres.)

Toda esta tipología se puede incrementar si tenemos en cuenta los remedios en los que la presencia del número nueve está intensificada porque, por ejemplo, hay nueve ingredientes que se aplican nueve veces al día durante nueve días, o... Podemos encontrar prácticamente todas las posibles combinaciones ${ }^{44}$. No es necesario dar cuenta de ellas porque no añadiría ninguna novedad cualitativa.

Encontramos casi la misma variedad en los remedios empleados para resolver las enfermedades de los animales domésticos (casi prolongaciones humanas), de los que en gran medida dependía la propia subsistencia. Daremos sólo un ejemplo de los muchos que se podrían traer aquí: en Asturias, a las vacas que no libraban, o que abortaban, se les daba una planta llamada golondrillu, en ayunas, durante nueve mañanas ${ }^{45}$.

Al presentar toda esta variedad de manifestaciones del número que nos ocupa, hemos ido seleccionando ejemplos de toda España (más alguno de Portugal) para hacer ver que no se trata de un fenómeno local. Por todas partes lo encontramos (más adelante veremos que su presencia no se limita

42 Ignacio María BARriola, La medicina popular en el País Vasco (San Sebastián: edicones vascas, 1979), p. 38.

43 Escoles nacionals de Sant Josep, Eivissa (bajo la dirección de Pere Planells i Mari), Remeis pagesos (Eivissa: Institut d'Estudis Eivissencs [Col-lecció *Nit de Sant Joan.], 1974), p. 32.

44 Por poner un ejemplo de acumulación de nueves, en Asturias, para eliminar el mal de filu de los niños, se parte un hilo en dos mitades, y en una de ellas, que se le anuda al cuello, se hacen nueve nudos; con la otra se frota al niño nueve veces y se van arrancando nueve hojas de laurel seco que se van quemando; a los nueve días se quema la otra (Luciano CASTAÑón, op. cit., p. 54).

45 Luciano CaStañón, «Datos y detalles de Sobrefoz (Ponga)", Archivum, XVIII (1968), p. 273. 
a la Península Ibérica y que ocupa un territorio mucho más amplio). Es cierto que no en todas las regiones tiene la misma presencia. Sobre la extendida norma general, destacan los casos de Galicia y Asturias, donde se consulte el repertorio etnomédico nos encontraremos con una abrumadora mayoría de usos del número nueve, y los del País Vasco y Canarias (una zona de habla no indoeuropea y otra de tardía neorromanización), donde, si bien no está ausente —como hemos visto-, sí ocupa una posición secundaria - compartida con otros nones- respecto del tres, que en estos casos es el número dominante ${ }^{46}$.

Ahora bien: ¿por qué este número?; ¿por qué tomar nueve ingredientes, por qué repetir nueve veces las operaciones? ¿Por qué un número tan alto? Sabemos que entre las tribus primitivas hay dificultades para contar por encima del cinco ${ }^{47}$. El origen del cómputo son los dedos; de ahí las bases quinarias, decimal y vigesimal. ¿Por qué entonces escoger un número que no es ni cinco ni diez ni veinte, y tan difícilmente reducible a ellos? ¿Qué hay detrás de él? ¿Qué se toma como referencia para que ocupe un lugar tan destacado en medicina popular? ¿Con cuál de sus valores simbólicos tienen que ver estas prácticas inmemoriales? ¿Es - como afirma Cirlot ${ }^{48}$ - "el número por excelencia de los ritos medicinales por representar la triple síntesis, es decir, la ordenación de cada plano (corporal, intelectual, espiritual)"? ¿Está relacionado "con los nueve meses en que el ser está en el vientre de su madre", o "con las grandes virtudes que se le atribuyen por su asociación con el ritual eclesiásticon?, como quiere Blázquez Miguel ${ }^{49}$.

Tal vez la pista nos la puede dar un famoso conjuro (el de Las doce palabras, también llamado de Los doce misterios o de Las doce palabras retornadas), eficaz contra cualquier daño o peligro, en el que a cada uno de los doce primeros números se le relaciona con algo (que cambia de un país a otro, de una región a otra) de lo que el número resulta ser símbolo ". La respuesta al nueve es "los nueve meses" o "los nueve meses

to En el caso canario, hay monografías en las que la presencia del tres es aplastante y el nueve no figura ni una sola vez, como en la de José Luis CONCEPCIÓN, Costumbres, tradiciones $y$ remedios medicinales canarios (Tenerife, 1984).

$4^{-}$Ésta puede ser una de las razones por las que en ocasiones encontramos el nueve como tres veces tres.

+* Op. cit., ibidem.

49 Juan BlázQlez Miguel, Hechicería y superstición en Castilla-La Mancha (Toledo: Servicio de Publicaciones de la Junta de Comunidades de Castilla-La Mancha [Monografías, 6], 1985), p. 83.

50 Son muchas las versiones, pero en esencia en todas alguien (el Demonio, un enemigo) pregunta a una persona qué es uno, qué es dos... Y este va dando respuestas 
que Jesús estuvo en el vientre de la Virgen" en versiones extremeñas, portuguesas, griegas, chilenas ${ }^{51}$ y de Nuevo México; alos nueve coros de ángeles" en versiones catalanas, portuguesas, italianas y alemanas; "los nueve cielos" en una versión asturiana (en la que todos los números tienen un simbolismo cristiano) ${ }^{52}$; son también "los nueve gozos de la Santa Virgen" en un cuento vasco, y "los templos de la Santísima Trinidad" en una versión portuguesa recogida por Adolfo Coelho ${ }^{53}$.

Los nueve meses, los nueve coros, los nueve gozos, los nueve templos de la Trinidad: la preñez, la perfección en que desemboca y el triple del tres. Pero parece que estos valores son postizos. Köhler, que investigó el origen de esta tradición ${ }^{54}$, dice que todas las versiones tienen una fuente común, probablemente persa. De los persas pasaría a los musulmanes y de éstos a los judíos, que la extenderían por Europa antes de la Edad Media. Las correspondencias con los nueve meses de gestación de Cristo, con los nueve coros angélicos, etc., serían adaptaciones cristianas posteriores, a las que tan bien se presta. En un canto kirguís se cuenta la historia del profeta Aesrät Ali que, habiendo prometido pagar la deuda de un creyente pobre, anda buscando dinero. Una calandria lo lleva a una ciudad de infieles, donde es hecho prisionero. Si no responde a diez preguntas del infiel Mulla, morirá. Las contesta y a su vez plantea otras tres al infiel, que contesta y se hace muslumán. El profeta vuelve rico y paga la deuda. Las diez preguntas son: ¿qué es uno?, ¿qué es dos?... La respuesta al nueve es: "Nueve, los nueve hijos del profeta Ibrahim" ". Köhler cree que esta versión se basa en otra más antigua, también musulmana, que a su vez deriva de una historia que se conserva en una narración pehlevi (de la antigua Persia), donde se cuenta que el hechicero Akht quiere destruir la ciudad de los adivinadores y que para ello manda un reto a uno de sus habitantes, el piadoso Ghôst-i-Fryânô, al que propone 33 enigmas, que si no resuelve supondrán su muerte. Pero los resuelve y mata al hechicero con una fórmula sagrada. Entre los enigmas están: ¿qué es uno?, ¿qué es

como: uno es Dios, dos las tablas de Moisés, etc., que acaban poniendo en fuga al adversario.

51 Julio Vicuña CIFUENTES, Estudios de folk-lore chileno. Mitos y supersticiones recogidos de la tradición oral chilena (Santiago de Chile: Imprenta Universitaria, 1915), pp. 133-156.

52 Luciano CaSTAÑón, op. cit., p. 39.

53 Adolfo COELHO, "Notas e parallelos folkloricos. II As doze palavras retornadas", Revista Lusitana, I (1887), pp. 246-259.

54 Coelho, ibidem, resume su investigación. Vid. la bibliografía que maneja.

55 Curiosamente, la respuesta al diez es "los diez meses de preñez. (También Ovidio dice que los meses de embarazo de la mujer son diez.) 
dos?... Así hasta diez. La respuesta al nueve es: «Nueve son las nueve aberturas del cuerpo humanon. Ésta parece la respuesta en la versión más antigua del conjuro (o de la historia de la que saldrá el conjuro).

El Germà Joan, curandero de Tarrasa del que hablamos antes, expresaba la creencia, antigua y popular, de que las enfermedades están provocadas por malos espíritus, y no son procesos que afecten a un órgano que se pueda tratar independientemente ${ }^{56}$. Estos espíritus pueden entrar o salir por los orificios del cuerpo humano. Publio Hurtado contó cómo era un exorcismo en la Extremadura de 1901. Se llevaba al poseso en ayunas al templo, atado de pies y manos. Se le hacía beber un brebaje que contenía ruda, mientras se rezaban oraciones, acompañadas de asperges. El cura entonces ordenaba salir a Satanás de aquel cuerpo. "Ya impelido a abandonarlo, y después de sostener a veces sofística discusión con el exorcista, le preguntaba que por dónde había de salir del cuerpo del endemoniado: si por los ojos, los oídos, las narices u otro conducto de su persona, concluyendo el preste por ordenarle que saliese por la boca, como vía más expedita y menos molesta para el poseídon. A continuación éste vomitaba algo negro que se filtraba por las losas del suelo ${ }^{57}$.

La creencia de que el mal entra o sale por los orificios del cuerpo está presente -conscientemente o no- en este tipo de prácticas. Incluso se pueden utilizar elementos de ayuda, según esta concepción. Elsa López Rodríguez, al tratar de aclarar el simbolismo del empleo de agujas en la medicina popular canaria, dice que "las agujas abren el cuerpo al exterior haciéndolo vulnerable a través de sus orificiosn ${ }^{58}$.

Es de todos conocida la costumbre de decir "Jesús" (o "Jesús, María y José", o "Dios te salve"), cuando alguien estornuda, "para dar gracias al Señor por haber expelido al diablo en la fuerte y ruidosa espiración" o "para conjurar el que entrase el demonio cuando ampliamente se abre la boca para hacer la inspiración preliminar" ${ }^{59}$. También el bostezo es momento peligrosamente propicio para que entren "los espíritus malos por el orificio bucal, por lo que es costumbre hacer la señal de la cruz sobre los labios" ${ }^{60}$.

En la creencia popular, este tráfico de espíritus se puede realizar por las aberturas que parecen menos apropiadas. Y no sólo en la creencia popular. A. Cardoner, al estudiar las fuerzas ocultas, en el pensamiento

\footnotetext{
56 Montserrat Puigdengolas y Regina Miranda, op. cit., p. 29.

" Publio Hurtado, op. cit., p. 103.

5* "La simbología en la medicina popular canaria", RDTP, XIII (1987), p. 129.

59 Antonio Castillo de luCAS, op. cit., p. 143.

0) Moisés MARCoS DE SANDE, "Del folklore Garrovillano", Revista de Estudios Extremeños, 1947 (III), p. 92.
} 
medieval, nos ha enseñado cómo Arnaldo de Vilanova y Roger Bacon "sostuvieron la posibilidad de la fascinación, suponiendo la proyección de los "spiritus" que saliendo de los ojos del agente influirían en el sujeto paciente o fascinado" ${ }^{61}$. La doctrina aún se aceptaba en el siglo XVI. Fray Martín de Castañega - en la línea de Martín del Río, de Pedro Ciruelo, de Gaspar Navarro, martillos de la superstición ${ }^{62}$ - lo racionaliza un tanto, y en lugar de hablar de espíritus habla de impurezas, las más sutiles de las cuales el cuerpo expele por "las vidrieras de los ojos; y así salen por los ojos, como unos rayos, las impuridades y suciedades más sotiles del cuerpo, y cuanto más sotiles, tanto más penetrantes y más inficionan " ${ }^{63}$. Esta concepción nunca desapareció de la mentalidad popular. Basta echar un vistazo a cualquier repertorio de supersticiones para ver la importancia que se le da al mal de ojo.

No es difícil encontrar huellas, en la terapéutica propular, de la creencia de que las enfermedades son "algo" que ha entrado en el cuerpo y que su curación pasa por sacarlo de él. En algunas partes de Galicia, el ensalmo que hay que recitar para la cura de la tiriza, tiricia, tiriz o eteriza (ictericia) dice (se ha llevado al enfermo antes de amanecer a la orilla de un río y se le ha sentado al pie de una "carrasca"): "Carrasca, carrasca / te vengo a visitar sin sol, / sácame la Etericia / que me da dolor. / Con el poder de Dios / y de la Virgen María, / un Padre Nuestro / y un Ave María / a la Santísima Virgen Marían. Al acabar el ensalmo, el enfermo debe coger dos hojas de carrasca y tirarlas al río, y se debe repetir la operación nueve días seguidos ${ }^{64}$. Este otro recitado contra el aojamiento que padecía una niña de Bande (Orense) lo oyó Risco: "le pusieron en la frente un poco de sal, y dijeron: "Así como pongo esta sal de la mar sagrada, se sale de aquí esta mala mirada. Por la gracia de Dios y de la Virgen María". Se rezan nueve padrenuestros y nueve Avemarías, y sale

61 A CARDONER, "Las fuerzas ocultas; formas de las supersticiones medievales", RDTP, XIX (1963), p. 379.

62 Con respecto al empleo de números en algunas curaciones, Gaspar NAVARRO (Tribunal de superstición ladina [Huesca, 1631]), dice: "Y usar de cosas sagradas, poniendo la confiança en el tiempo, y numero, el qual no tiene virtud, ni fuerça para causar tales efectos, ni viene por institucion de Dios, ni de la Iglesia, es supersticion. (p. 78a); y a...el efecto que se sigue por la esperança del numero, no es natural, ni sobrenatural, ni recibido por la Iglesia. Luego es, y proviene por pacto explicito, ò implicito del Demonion (p. 78b).

63 Fray Martín de CASTAÑEGA, Tratado de las supersticiones y bechicerias, edición de Agustín González de Amezúa (Madrid: Sociedad de Bibliófilos Españoles [Segunda época, XVII], 1946 - la primera edición es de Logroño, 1529-), pp. 71-72.

64 Elisardo Becoña Iglesias, op. cit., p. 66. 
la mala mirada" ${ }^{65}$. Contra el dolor de muelas, en Asturias se dice tres, cinco o nueve veces (hay que esperar a que haya luna nueva): "Dios te bendiga / llúa nova / que nun morda / can nin culobra / nin me dola / dente nin mola / nin m'entre ningún mal de fora" ${ }^{66}$.

La protección de las nueve vías de comunicación del organismo con el exterior puede ser el motivo original -y seguramente ya olvidadoque subyace en la presencia recurrente del número saludador por excelencia. Como no se sabe por cuál de las puertas ha entrado -o puede entrar - el mal, hay que buscar un procedimiento que alcance a cada una de ellas. Hay que obligarlo a que salga $\longrightarrow$ impedirle que entre - dirigiendo una instrucción que tenga en cuenta por igual a todas las aberturas. No cumplir esta condición puede suponer que la enfermedad entre por un acceso desprotegido, o que no salga del todo porque no se la ha obligado a hacerlo por todas las salidas. Un remedio para cada orificio.

En un tratadito catalán del siglo XV, atribuido a Manuel Dies de Calatayud, mayordomo de Alfonso el Magnánimo, se recoge una serie de fórmulas para la confección de afeites y de medicamentos, con las proporciones para cada preparado, tiempos de aplicación, etc. ${ }^{67}$ Curiosamente, aquí, en todos los remedios que se refieren a algún orificio del cuerpo humano interviene el número nueve: contra el mal aliento, para la mujer que a menudo aborta, contra el dolor de ojos o el lagrimeo constante. Sin embargo, los depilatorios, los limpiadores de piel, los blanqueadores, los remedios contra el dolor de cabeza, los teñidores, este tipo de productos están asociados a números como el tres, el diez, el cinco, el seis, el dos, el ocho, el quince; nunca al nueve.

Ahora bien, que el cuerpo tiene nueve soluciones de continuidad es más una creencia que un hecho. También se podrían contar como aberturas, por ejemplo, los poros de la piel (de hecho, Fray Martín de Castañega, al hablar de las "ventanas" por las que el cuerpo "expelle" todo aquello que "no se torna en sustancia y mantenimiento del cuerpo", nombra los que venimos llamando nueve orificios y "los poros y partes espongiosas" ${ }^{68}$ ). Los vascos posiblemente consideran que el cuerpo tiene más aberturas. Erkoreka, en

"5 Vicente Risco, "Apuntes sobre el mal de ojo en Galicia", RDTP, XVII (1961), pp. $87-88$.

6 Lluisa Castro Menéndez y Xosé Antón González Riaño, "Dellos aspeutos máxicos nel folklor de Villayón», Lletres Asturianes, 13 (1984), p. 64.

6- Flores del tesoro de la belleza. Tratado de muchas medicinas o curiosidades de las mujeres (Palma de Mallorca: José J. de Olañeta Editor, 1993).

Fray Martín de CASTAÑEGa, op. cit., pp. 71-72. 
su análisis de la medicina popular vasca, dedica un apartado a las "precauciones con las puertas de entrada u orificios del organismon, en el que habla de los "puntos concretos, la boca, las fosas nasales, el ano, el meato urinario, la vagina y en menor escala los conductos auditivos y el ombligo, en los que la mentalidad popular hace un especial hincapié cuando se trata de la defensa del organismo contra los agentes externos" ${ }^{69}$. Si añadimos los ojos, tal vez las dos ventanas más evidentes en el pensamiento popular, obtenemos un número de orificios diferente (quizá se deba a esto el que en la etnomedicina vasca el nueve no tenga el papel preponderante que tiene en la de otros pueblos).

Por gran parte de Europa encontramos usos del nueve en la terapéutica popular: en Portugal ${ }^{70}$, en Francia ${ }^{71}$, en Inglaterra ${ }^{72}$, en Italia (en Sicilia, se teme hacer desaparecer la erisipela antes del noveno día ${ }^{73}$, tal vez porque se desconfía de que el mal desaparezca antes de haberlo expulsado adecuadamente).

En algunos repertorios americanos, lo mismo si cubren zonas amplias como pequeños núcleos, si son poco precisos con las cantidades o con las cifras que intervienen en cada caso, como si las consignan meticulosamente ${ }^{74}$, no aparece el número nueve. Casi siempre, de manera abruma-

69 Op. cit., pp. 59-60.

70 Ver Claudio BASTO, "Medicina popular", Revista Lusitana, XXIV (1921-1922), p. 22; Belarmino AfONSO, "Concepción y nacimiento. Aspectos de un rito de paso", RDTP, XLIII (1988), pp. 15-16, 19; también los artículos citados en las notas 9 y $21, \mathrm{y}$ el título, más adelante, de la nota 74 .

71 Ver M. BOUTEILlER, Médecine populaire d'hier et d'aujourd'bui (Paris: Éditions G.-P. Maisonneuve et Larose, 1966), especialmente las páginas 269 a 320, donde aparecen, por ejemplo, nueve ingredientes (pp. 273, 278, 300..), o nueve oraciones o conjuros con cuentas descendentes desde el número nueve (pp. 294, 298...), u operaciones que se repiten durante nueve días seguidos (pp. 290, 292, 299...), etc. También, Robert JALBY, Sorcellerie \& Médecine populaire en Languedoc (Nyons: Éditions de l'Aygues, 1974); aquí se presentan separados, en capítulos distintos, los procedimientos tradicionales empíricos y los mágicos; hay multitud de éstos entre las páginas $161 \mathrm{y}$ 173, y prácticamente en todos interviene el número nueve.

i2 W. George BLACK, Medicina popular. Un capítulo en la bistoria de la cultura (Barcelona: Alta Fulla, 1982 [es facsímil de la primera edición, de 1889; la original inglesa es de 18831), pp. 77, 78, 92, 94, etc.

73 Giuseppe PITRE, Medicina popolare siciliana (Firenze: G. Barbèra Editore [Opere Complete di G.P., XIX], 1949), p. 226.

74 Ver Guillermo PERKINS HIDALGO, "Supersticiones recogidas en la provincia de corrientes", Cuadernos del Instituto nacional de Investigaciones Folklóricas, 1 (1960), pp. 159-167; Jesús María CARRIzo, "Algunas supersticiones medicinales del norte argentino", Cuadernos del Instituto Nacional de Investigaciones Folklóricas, 1 (1960), 
dora, es el tres; alguna vez, muy pocas, el cinco, el siete, el ocho. En la breve comparación de la terapéutica popular brasileña y portuguesa que hicieron A. Lima Carneiro y F. C. Pires de Lima ${ }^{75}$, vemos que en Brasil domina el tres - sólo en un caso surge el nueve-, mientras en Portugal el más frecuente es el nueve. Incluso, en una misma dolencia, en Brasil el procedimiento incluye el tres y en Portugal el nueve ${ }^{76}$. Ni siquiera hay rastros de él en un recetario copiado de la libreta de un curandero uruguayo 7 . Hay que irse a los repertorios que contienen métodos terapéuticos más abundantes e instrucciones más detalladas para encontrar el número nueve, siempre en clara minoría respecto del tres ${ }^{78}$. Esto siempre es así, incluso aunque el autor de la monografía nos advierta de que forma parte del grupo de los más repetidos. "Se notará, igualmente -dice Teodoro Vidal refiriéndose a Puerto Rico ${ }^{79}$-, que en estos remedios figuran con frecuencia los números impares, muy en especial el tres, el siete y el nueven; y de los alrededor de cuarenta remedios en que aparecen cifras, tan sólo en dos está presente el número nueve, mientras casi el resto está dominado por el tres. Entre los indicos zinacantecos, del suroeste de Méjico, una comunidad que ha mantenido sus tradiciones relativamente alejadas de influencias exteriores, cuando se precisa el número de operaciones o de elementos que intervienen en sus largos rituales curativos, éste también suele ser el tres ${ }^{80}$. El nueve está ausente incluso en los

pp. 169-175; Óscar VAldivia PONCE, Hampicamayoc. Medicina folklórica y su substrato aborigen en el Perú (Lima: Universidad Nacional Mayor de San Marcos, 1975); Eduardo Estrella, Medicina aborigen. La práctica médica aborigen de la sierra ecuatoriana (Quito: Editorial Época, 1977); Ana B. DE CARLIER, Asi nos curamos en el Canipaco. Medicina tradicional del Valle del Canipaco, Huancayo, Perú (1981).

$-\quad$ Notas comparativas de medicina popular luso-brasileira e notas comparativas entre o vocabulário médico popular português e o vocabulário médico popular brasileiro (Lisboa, 1940).

76 Por ejemplo, en males relacionados con el pie (pp. 16-17).

-- Ildefonso PEREDA VALDÉs, Magos y curanderos. Medicina popular y folklore mágico (Montevideo: Arca Editorial, 1968). Aparecen bastantes instrucciones de clara estirpe supersticiosa, en las que el número que más se repite es, con mucha diferencia, el tres.

-8 Vid. Julio Vicuña Cifuentes, op. cit.; José Joaquín Montes Giraldo, Medicina popular en Colombia. Vegetales y otras sustancias usadas como remedios (Bogotá: Publicaciones del Instituto Caro y Cuervo [núm. LVIII], 1981).

" "Aportación al estudio del folklore médico en Puerto Rico", Revista del Instituto de Cultura Puertorriqueña, 50 (1971), p. 53.

*o Horacio FABREGA, Jr. y Daniel B. SILVER, Illness and Shamanistic Curing in Zinacantan. An Ethnomedical Analysis (Stanford: Stanford University Press, 1973). Ver sobre todo las páginas 159 a 197 , dedicadas a las ceremonias de curación públicas y privadas conducidas por los b'iloletik, chamanes locales. 
procedimientos empleados para combatir una enfermedad tan temida y de tan claro aspecto supersticioso como el susto ${ }^{81}$. Aunque, aquí, la mentalidad popular no es ajena a la concepción de la enfermedad como penetración de un agente maligno en el cuerpo, la creencia que se tiene sobre el origen de este mal es muy distinta. No es nada exterior que se ha introducido en el organismo y que hay que expulsar, sino que algo hostil ha succionado el alma, la ha raptado, y anda extraviada, y todos los esfuerzos se dirigen a mostrarle el camino de vuelta, a irla conduciendo para que regrese al cuerpo ${ }^{82}$. Si bien no se puede descartar el origen autóctono del empleo (aunque escaso) del número nueve, es posible que su uso en Sudamérica provenga del contacto con los europeos. "Aunque los métodos curativos -opina Teodoro Vidal- que nuestro pueblo tradicionalmente emplea tienen matices autóctonos, ellos son, en su mayoría, de raigambre española ${ }^{83_{n}}$. (A. Castillo de Lucas ya nos informó de cómo algunos métodos llevados de Europa tuvieron gran acogida en América ${ }^{84}$.)

Tampoco entre los árabes parece tener presencia el número nueve. En un recetario médico árabe del siglo $\mathrm{XI}^{85}$ está ausente por completo, lo que resulta significativo, sobre todo teniendo en cuenta que entre los cientos de recetas figura una variedad tan amplia de números como el 1, el 2 , el 3, el 4, el 5, el 6, el 8, el 10, el 12, el 15, el 18, el 20, el 40 (sobre todo el tres, que parece el que más se repite). Y aunque se trata de recetas hechas con ingredientes naturales (semillas, frutos, hierbas, aguas...),

81 Sobre esta enfermedad, ver Arthur J. RUBER, Carl W. O'Nell y Rolando ColladoARDÓn, Susto, a folk illness (Berkeley: University of California Press, 1984).

82 Ver, por ejemplo, Zdzislaw RYN, Los Andes y la medicina (La Paz: Instituto Boliviano de Cultura [Fuentes para la Investigación y Documentación Andina, núm. 4], 1981).

83 Art. cit., p. 53.

84 "La medicina popular en Hispanoamérica. Influencia del Descubrimiento", Boletín de la Biblioteca Menéndez y Pelayo, XIII (1966), pp. 211-232. El artículo ofrece un amplio apéndice bibliográfico. Ver también el trabajo de Haydée SEIJAS, •Algunos aspectos de la medicina de los indios Sibundoy de Colombian, Boletin Informativo (Caracas: Instituto Venezolano de Investigaciones Científicas), 6 (1969), donde habla - p. 13de las influencias exteriores incluso en la concepción indígena de la enfermedad; y Beatrice A. ROEDER, Chicano Folk Medicine from Los Angeles, California (Los Angeles: University of California Press [Folklore and Mythology Studies, vol. 34], 1988), p. 39, n. 3, donde compara un remedio chicano contra una afección cutánea, con otro espanol para combatir la erisipela, y en el que la manteca chicana sustituye al aceite de oliva español.

85 Ibn WAFID DE TOLEDO, El libro de la almohada, edición de Camilo Álvarez de Morales y Ruiz-Matas (Toledo: Instituto Provincial de Investigaciones y Estudios Toledanos [Serie Segunda: *Vestigios del pasado", núm. 7], 1980). 
mezcladas en proporciones posiblemente eficaces y avaladas por un uso prolongado desde mucho tiempo atrás, no faltan, al menos en algunas de ellas, elementos llamemos mágicos, o supersticiosos, como exponer un preparado veinte días al sol, o repetir la operación ese mismo número de veces, o emplear trigo que tenga tres años, o aplicar sangre de conejo para eliminar las pecas, etc.

Por otra parte, el judío Ishaq Israeli, nacido en Egipto en el siglo noveno, da como los mejores días para que cese una enfermedad el séptimo y el decimocuarto (en segundo y en tercer lugar están los quinto, noveno y decimoséptimo, y tercero, undécimo y vigésimo primero, respectivamente ${ }^{86}$ ).

Por lo que respecta a África, si hiciésemos extensivo el resultado del examen de los remedios populares ruandeses ${ }^{87}$ al resto del continente, tendríamos que en él, a pesar de que no faltan números como el tres, el cuatro o el cinco, y aunque a menudo haya cierta imprecisión ("dos o tres", se repite en muchas ocasiones), el número que rige es, curiosamente, el dos ${ }^{x 8}$ (del que, como par vitando, siempre hay, al menos en el resto de lugares que hemos visto, instrucciones expresas de huir), y que el nueve no se presenta nunca.

De los números que intervenían en la terapéutica popular del mundo clásico, nos ha llegado muy poco. Pero al menos disponemos de un testimonio que nos permite asegurar que el nueve figuraba en ella. Es de Plinio, y en él se hace eco de algo que ha oído: "Dicen [aiunt] que si se cogen nueve granos y se traza con cada uno de ellos tres veces un círculo alrededor de un forúnculo, con la mano izquierda, y después se arrojan al fuego, el forúnculo desaparece enseguida" ${ }^{89}$. Y Dioscórides dice que las fiebres tercianas se curaban (ya hemos dicho que esto puede ser un disfraz del nueve o un refuerzo del tres) con tres raíces de llantén, tres vasos de vino y tres de agua ${ }^{90}$.

* Tratado de las fiebres, edición del P. José Llamas (Madrid: CSIC [Instituto Arias Montano de Estudios Hebraicos y Oriente Próximol. 1945), p. 130.

$x^{*}$ A. Lestrade, La médecine indigène au Ruanda (Bruxelles: Académie Royale des Sciences Coloniales [Classe de sciences morales et politiques, mémoires in-8. ${ }^{\circ}$, nouvelle série, tomo VIII, fasc. 1 [Ethnographiel], 1955).

* Se aplica un remedio dos veces al día, se cogen plumas y huesos de dos pájaros. se hacen dos cortes en munecas y codos, se toma una poción en dos veces, se pasa al enfermo entre dos lanzas, se emplean dos bayas, o dos hojas, se entierra algo durante dos días, se permanece ese tiempo en cama...

80 Maria Cristina MARTINI, Piante medicamentose e rituali magico-religiosi in Plinio (Roma: Bulzoni editore [Biblioteca di Cultura, 125], 1977), p. 34.

9) Luis GIL, Therapeia. La medicina popular en el mundo clásico (Madrid: Ediciones Guadarrama [Colección Guadarrama de crítica y ensayo, 50], 1969), p. 242. El nueve, 
En la India, los sabios del siglo $\mathrm{V}$ tenían varios nombres para cada una de las cifras base de su sistema de numeración decimal. Como las tablas numéricas y los tratados matemáticos y astronómicos los transmitían versificados (el ritmo ayudaba a fijarlos en la memoria), ello permitía elegir el que más convenía según las necesidades del verso. Uno de los nombres del número nueve era "los orificios del cuerpo humano" ${ }^{91}$.

Esta visión de conjunto, no exhaustiva, parece indicar que la distribución del empleo del número nueve en la medicina popular no es arbitraria, o casual. Tal vez se podría conjeturar que la creencia de que el cuerpo humano tiene nueve orificios - y con ella, los ritos curativos que lleva aparejados- es de origen indoeuropeo; aunque eso ya está fuera de nuestros propósitos iniciales y del alcance de este trabajo, que no era otro que tratar de encontrar una explicación de la presencia recurrente del número nueve en la terapéutica popular.

\section{EMILIO GAVILANES}

Instituto de Lexicografía de la Real Academia Española

\footnotetext{
esta vez junto con el siete, también tenía entre los griegos una consideración especial en los asuntos de la salud. Se llamaba klimaktēres o klimaktērikoi eniautoi a los años de la vida humana en los que podían sobrevenir las mayores desgracias (de salud, aunque también de fortuna). $Y$ esos años climatéricos seguían ciclos de nueve o de siete (p. 454).

91 Georges IFRAH, Las cifras. Historia de una gran invención (Madrid: Alianza, 1987), pp. 257-261.
} 
La pregunta que plantea este trabajo es por qué aparece tanto el número nueve en la terapéutica popular. Qué simbolismo se esconde tras su empleo. Se empieza clasificando mitos y ritos en los que interviene el nueve, para agruparlos y extraer de cada grupo su posible simbolismo último. A continuación se estudia toda la variedad de formas en que aparece el nueve en diferentes remedios españoles. El estudio de un conjuro, eficaz contra cualquier mal, y de la concepción de la enfermedad en la mentalidad popular, permite proponer una respuesta a la pregunta planteada. Por último se estudia la distribución en diferentes países y culturas de los números que dominan en sus respectivos procedimientos.

The reason why the number nine appears so widely in the popular therapeutics is the question this research attempts. What symbolism is hidden behind its use. It is started by classifying myths and rites in which the number nine participates, in order to both group them and extract the potential ultimate symbolism from each group. Further, the overall variety of forms in which the number nine appears in different spanish remedies is analyzed. The study of an exorcism, effective against any harm, as well as of the notion of the illness in the popular mentality, allows to propose an answer to the question stated. Finally, the distribution of the numbers that govern in the corresponding procedures throughout different countries and cultures is studied. 